\title{
Placement of Hemodialysis Catheters Through Stenotic or Occluded Central Thoracic Veins
}

\author{
Claude Haller · Sébastien Déglise · Francois Saucy • \\ Claudine Mathieu $\cdot$ Erik Haesler $\cdot$ Francesco Doenz $\cdot$ \\ Jean Marc Corpataux · Salah Dine Qanadli
}

Received: 22 May 2008/Accepted: 2 April 2009/Published online: 16 May 2009

(C) Springer Science+Business Media, LLC and the Cardiovascular and Interventional Radiological Society of Europe (CIRSE) 2009

\begin{abstract}
A method for hemodialysis catheter placement in patients with central thoracic venous stenosis or occlusion is described and initial results are analyzed. Twelve patients, with a mean age of 63.2 years ( $42-80$ years), with central venous stenosis or occlusion, and who required a hemodialysis catheter were reviewed. All lesions were confirmed by helical CT or phlebography. Five patients had stenosis while seven patients were diagnosed with an occlusion of thoracic central veins. All patients were asymptomatic, without sign of superior vena cava syndrome. After percutaneous transstenotic catheterization or guidewire-based recannalization in occlusions, a balloon dilatation was performed and a stent was placed, when necessary, prior to catheter placement. Technical success was $92 \%$. Three patients had angioplasty alone and nine
\end{abstract}

C. Haller · S. Déglise $\cdot$ F. Saucy · J. M. Corpataux

Unit of Thoracic and Vascular Surgery, CHUV-University of Lausanne, Rue du Bugnon 46, Lausanne 1011, Switzerland

C. Haller

e-mail: claude.haller@rsv-gnw.ch

C. Mathieu

Unit of Nephrology, CHUV-University of Lausanne,

Rue du Bugnon 46, Lausanne 1011, Switzerland

E. Haesler

Unit of Vascular Medicine, CHUV-University of Lausanne, Rue du Bugnon 46, Lausanne 1011, Switzerland

F. Doenz · S. D. Qanadli

Unit of Interventional Radiology, CHUV-University

of Lausanne, Rue du Bugnon 46, Lausanne 1011, Switzerland

S. D. Qanadli $(\bowtie)$

Department of Radiology, CHUV-University of Lausanne,

Rue du Bugnon 46, 1011 Lausanne, Switzerland

e-mail: salah.qanadli@chuv.ch patients had angioplasty with stent placement. Dialysis catheters were successfully inserted through all recannalized accesses. No immediate complication occurred, nor did any patient develop superior vena cava syndrome after the procedure. The mean follow-up was 21.8 months (range, 8-48 months). Three patients developed a catheter dysfunction with fibrin sheath formation (at 7, 11, and 12 months after catheter placement, respectively). Two were successfully managed by percutaneous endovascular approach and one catheter was removed. In conclusion, for patients with central venous stenosis or occlusion and those who need a hemodialysis catheter, catheter insertion can be reliably achieved immediately after endovascular recannalization with acceptable technical and long-term success rates. This technique should be considered as an alternative procedure for placing a new hemodialysis catheter through a patent vein.

Keywords Dialysis catheter - Angioplasty ·

Central venous stenosis $\cdot$ Stents $\cdot$ Venous access

\section{Introduction}

Hemodialysis catheters (HCs) are widely used in dialyzed patients even if they are placed only because other types of hemodialysis access are not available or are not yet available (immature fistulas). Temporary HCs are indicated in patients who need a $\mathrm{HC}$ before a permanent arteriovenous fistula has been performed and in those with arteriovenous fistula dysfunctions who need a major surgical revision of their fistula. Permanent HCs are used in patients with no alternative options for chronic dialysis access. However, catheters still have a high risk of infections (up to $50 \%$ ) and fibrin sheath formation (40-50\%) [1-4], which 
may induce venous obstructions and subsequent catheter dysfunction. In cases of mechanical-related complications such as venous and catheter obstructions, the catheter has to be removed and another one then placed. Furthermore, frequent catheter changes in central thoracic veins (CTVs) might lead to their early obstruction, comprising future access for hemodialysis. If the catheter is inserted in another CTV, a new thrombosis may also induce superior vena cava syndrome and the route for a future arteriovenous fistula could be compromised. In cases with no patent access to the superior vena cava, the $\mathrm{HC}$ can be placed in the inferior vena cava. However, the incidence of infection is higher with HCs in the inferior vena cava, due to the femoral access in the groin $[5,6]$. An alternative option is to use the occluded route for $\mathrm{HC}$ placement to avoid potential consequences of venous obstruction after $\mathrm{HC}$ placement [7-10]. We report our experience with CTV recannalization in asymptomatic patients in order to place a HC. The purpose of the study was to evaluate the feasibility of placement of HCs in stenosed or occluded CTVs in asymptomatic patients: technical success and procedure safety were the primary end points of the study.

\section{Materials and Methods}

Between April 2002 and June 2005, patients at risk of having CTV obstruction (patients with previous implanted central venous catheters, patients with known CTV obstruction, and patients who had catheter placement failure) and who needed HC placement were first screened with ultrasound and or CT phlebography of the CTV and were then treated according to our institutional guidelines (Fig. 1). If there was any suspicion of venous obstruction at ultrasound or CT phlebography, the CTV circulation was evaluated by phlebography prior to $\mathrm{HC}$ placement.

During this period, 12 patients who were candidates for HC placement had CTV stenosis or occlusion. All patients were long-term-dialyzed patients with numerous prior arteriovenous fistulas or $\mathrm{HCs}$ and needed a new $\mathrm{HC}$ for two different indications: patients who needed a permanent $\mathrm{HC}$ because there was no other option to create an arteriovenous fistula $(n=5)$, and patients who needed a temporary HC because of major surgical revision on an arteriovenous fistula $(n=7)$. The mean age was 63.2 years (range, 42-80 years) (Table 1 summarizes demographic data on the study population). All patients were asymptomatic before the procedure regarding CTV obstruction (the Kishi score for clinical signs of superior vena cava [SVC] obstruction was $<4$ for all patients). Helical CT phlebography using the technique described by Qanadli et al. [11] $(n=2)$ or digital phlebography $(n=11)$ was done prior to the procedure to evaluate the CTV circulation including

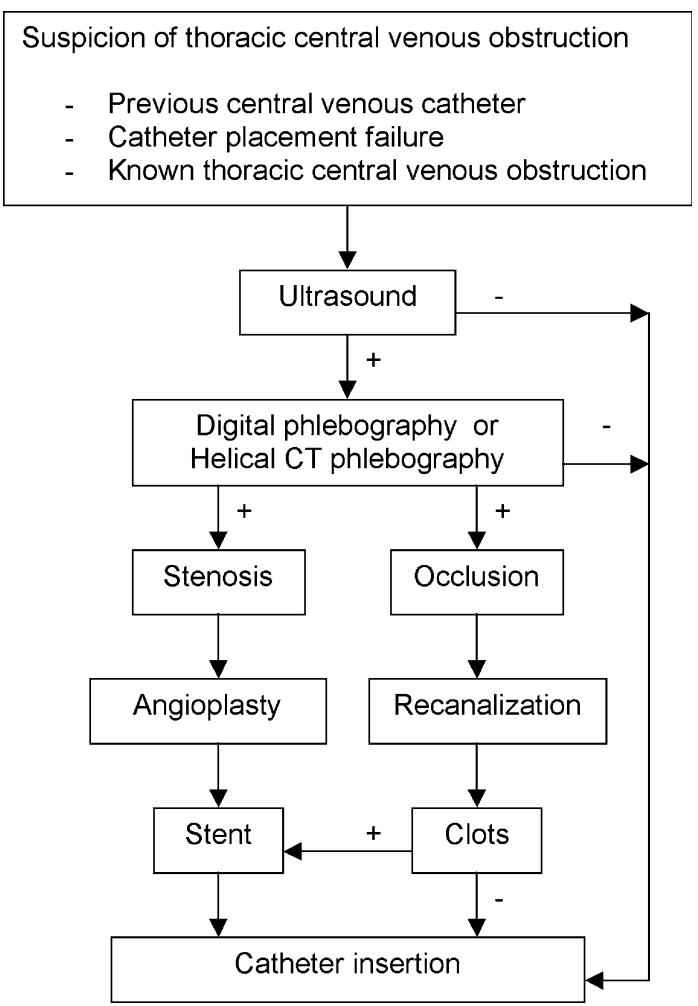

Fig. 1 Institutional flowchart for hemodialysis catheter placement in patients with central vein obstruction

stenosis and occlusion evaluation and collateral supply assessment. In one patient, helical CT phlebography failed and a digital phlebography had to be performed. Five patients had stenosis, four located on the left brachiocephalic vein and one on the right brachiocephalic vein, while seven other patients had occlusion. Three occlusions were located on the brachiocephalic vein, and two in the SVC. Two patients had occlusion of the SVC and stenosis of the left brachiocephalic vein. The side for HC placement was chosen according to the venous obstruction or occlusion and leaving the patent veins free for cerebral venous drainage and future dialysis access. According to previous studies [12], we used the jugular access for HD catheter insertion first whenever it was possible. The subclavian access was used as a second choice for HD placement. All patients gave their informed consent for the procedure. Procedures were performed in the interventional suite using standard digital fluoroscopic equipment. Seven procedures were performed under local anesthesia and the remaining five were performed under general anesthesia. Two patients refused local anesthesia and in three patients we expected a long procedure time and the patients preferred general anesthesia based on previous experience. Five patients were outpatients and seven patients were hospitalized for their shunt revision. Nine patients were on aspirin prior to the procedure, two were on coumarin, and 
Table 1 Demographic data on the study population

\begin{tabular}{|c|c|c|c|c|c|}
\hline Patient no. & Gender & Age (year) & Arteriovenous fistula & Stenosis & Occlusion \\
\hline 1 & $\mathrm{~F}$ & 80 & None & & Left BCV \\
\hline 2 & $\mathrm{~F}$ & 69 & None & SVC & Left BCV \\
\hline 3 & M & 43 & Upper arm prosthetic fistula & & Left BCV \\
\hline 4 & $\mathrm{~F}$ & 63 & Upper arm prosthetic fistula & & SVC \\
\hline 5 & M & 50 & None & SVC & Left BCV \\
\hline 6 & M & 69 & None & Left BCV & \\
\hline 7 & M & 49 & Forarm prosthetic fistula & Left BCV & \\
\hline 8 & $\mathrm{~F}$ & 68 & Forarm prosthetic fistula & & Right BCV \\
\hline 9 & M & 77 & None & Right BCV & \\
\hline 10 & M & 44 & Native radiocephalic fistula & & SVC \\
\hline 11 & M & 68 & Upper arm prosthetic fistula & Left BCV & \\
\hline 12 & M & 78 & Forarm prosthetic fistula & Right BCV & \\
\hline
\end{tabular}

Note: $F$ female, $M$ male, $S V C$ superior vena cava, $B C V$ brachiocephalic vein

one had neither aspirin nor coumarin. After stenting, the patients were on long-term aspirin or coumarin as they were before. Anticoagulants were given intravenously (3000-5000 IU of sodium heparin) during the procedure. A single dose of $1 \mathrm{~g}$ of vancocin as antibiotic prophylaxis was also given before the procedure.

\section{Revascularization Technique}

The right femoral vein $(n=10)$, the jugular vein $(n=3)$, or the fistula $(n=2)$ was punctured with an 18-gauge needle. We used the femoral or the shunt as the first choice of access depending on the location of the obstruction. In two situations, we had an occlusion of the left brachiocephalic vein and a stenosis of the SVC. In these situations, we used the only drainage of the head as access for the $\mathrm{HC}$; it is essential to keep permeability of the vein with a stent.

(a) In patients with complete venous obstruction $(n=7)$, a balloon angioplasty was done after recannalization until a sufficient diameter was reached to allow $\mathrm{HC}$ placement. Considering the $\mathrm{HC}$ size, a $10-\mathrm{mm}$ balloon (balloon pressure ranging from 6 to 12 atm) was used. A gradual angioplasty was done where necessary, starting with a balloon of $6 \mathrm{~mm}$. If the optimal diameter was not reached with balloon dilatation $(n=2)$ alone, as well as in patients with clot formation at the site of dilatation $(n=3)$, a selfexpanding stent was deployed (five of seven) to improve the diameter, facilitate $\mathrm{HC}$ implantation, and prevent distal emboli during $\mathrm{HC}$ implantation (Fig. 2). The distal extremity of the stent required precise deployment to make sure that the $\mathrm{HC}$ could be inserted into the stent. For this reason, Nitinol-based self-expanding stents were preferred. A phlebography was obtained at the end of the procedure to check for adequate release and location of the stent, as well as patency of the venous system, before HC placement.

(b) In patients with venous stenosis $(n=5)$, a balloon angioplasty was done (balloon pressure ranging from 6 to $12 \mathrm{~atm}$ ) (Fig. 3); if the optimal diameter was not reached with balloon dilatation (residual stenosis $<30 \%)$, a self-expanding stent $(n=4)$ was deployed to avoid occlusion of the vein after $\mathrm{HC}$ insertion. Phlebography was obtained to check for adequate release and location of the stent and patency of the venous system. In patients with complex stenosis or occlusions, we used a combined approach by a femoral and jugular access.

(c) For the $\mathrm{HC}$ insertion technique, an 18-gauge needle puncture was used to gain access to the jugular vein, if this was not already done for venous recannalization, or to the subclavian vein as second choice. For a temporary HC, the short-term 11.5-Fr Duo-Flow XTP with 20-cm double-lumen catheter (Medcomp, Harleysville, PA, USA) was used. The $\mathrm{HC}$ was fully inserted, the catheter tip was positioned in the right atrium junction under fluoroscopic guidance, and the $\mathrm{HC}$ was sutured into position. The HC was checked for backflow and flushed with heparin solution.

For a permanent HC, the long-term catheter 10-Fr BioFlex Tesio with football cuff ( $27-\mathrm{cm}$ arterial, $30-\mathrm{cm}$ venous cuff placement; Medcomp) was used. The two HCs were fully inserted and the catheter tips were positioned in the right atrium junction with the SVC under fluoroscopic guidance (Fig. 4). The HCs were checked for backflow and flushed with heparin solution.

In three patients, the $\mathrm{HC}$ could not be advanced through the recannalized access: a 6-Fr, 25-mm Amplatz Goose Neck snare device (EV3, Plymouth, MA, USA) was introduced by the femoral approach through the 
Fig. 2 An 80-year-old woman with chronic kidney disease (diabetes and hypertension) who was dialyzed for 4 years. After failure of peritoneal dialysis, she had a left jugular dialysis catheter inserted, which was removed for dysfunction due to a pericatheter thrombosis. Another catheter was inserted into the right subclavian vein. It also had to be removed, due to for dysfunction, and a temporary femoral catheter was placed. Phlebography of the thoracic venous circulation, by a right femoral approach, shows occlusion of the right and left brachiocephalic veins and a stenosis of the superior vena cava. The left jugular vein is patent (A). Angioplasty of the left brachiocephalic vein was performed (B) and a selfexpanding stent $(10 \times 80 \mathrm{~mm})$ was placed $(\mathbf{C})$ from the left jugular vein through the left brachiocephalic vein into the superior vena cava. At the end, patency of the stent was controlled by phlebography (D)
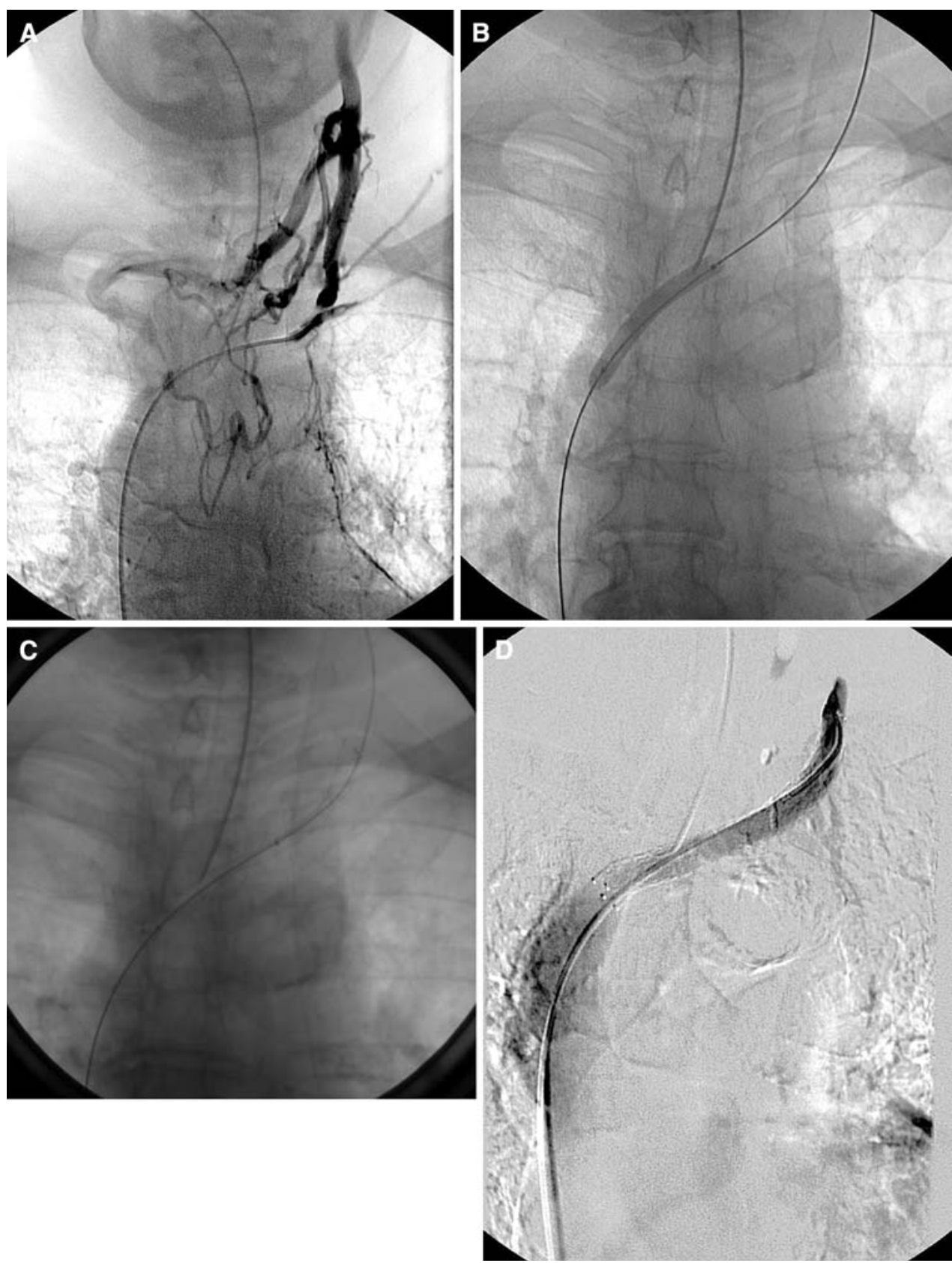

recannalized access to trap the $\mathrm{HC}$ catheter in the jugular or the subclavian vein and facilitate the pulling maneuver through the stent or stenosis site into the SVC. At the end of the procedure, a controlled fluoroscopy was done to check the accurate position of the HC.

\section{Complications}

All complications during the procedure or related to the procedure were reported. After the procedure, all patients were followed at the dialysis center and all catheter dysfunctions or symptoms of venous obstruction were reported. All complications related to the $\mathrm{HC}$ were noted during the time that the $\mathrm{HC}$ was in place. If a $\mathrm{HC}$ dysfunction was reported, phlebography was performed to evaluate the $\mathrm{HC}$ dysfunction. If it was not used, the $\mathrm{HC}$ was removed. After $\mathrm{HC}$ removal, the patient was only clinically followed up for SVC syndrome; no phlebograhy was performed to assess the venous permeability during follow-up.

\section{Results}

Revascularization procedures were done by the femoral approach alone in seven patients (58\%). A combined jugular and femoral approach was necessary in long occlusion 
Fig. 3 A 79-year-old man with chronic kidney disease, dialyzed for 12 years. In the past, many central venous catheters had been placed on both sides. He had surgery on his left right arm arteriovenous fistula and needed a temporary catheter for dialysis. Phlebography of the thoracic venous circulation by a right femoral access shows stenosis of the superior vena cava (A). An angioplasty was performed with a 14/40-mm balloon (B). Control phlebography shows no residual stenosis on the superior vena cava (C) and a patent left brachiocephalic vein (D)
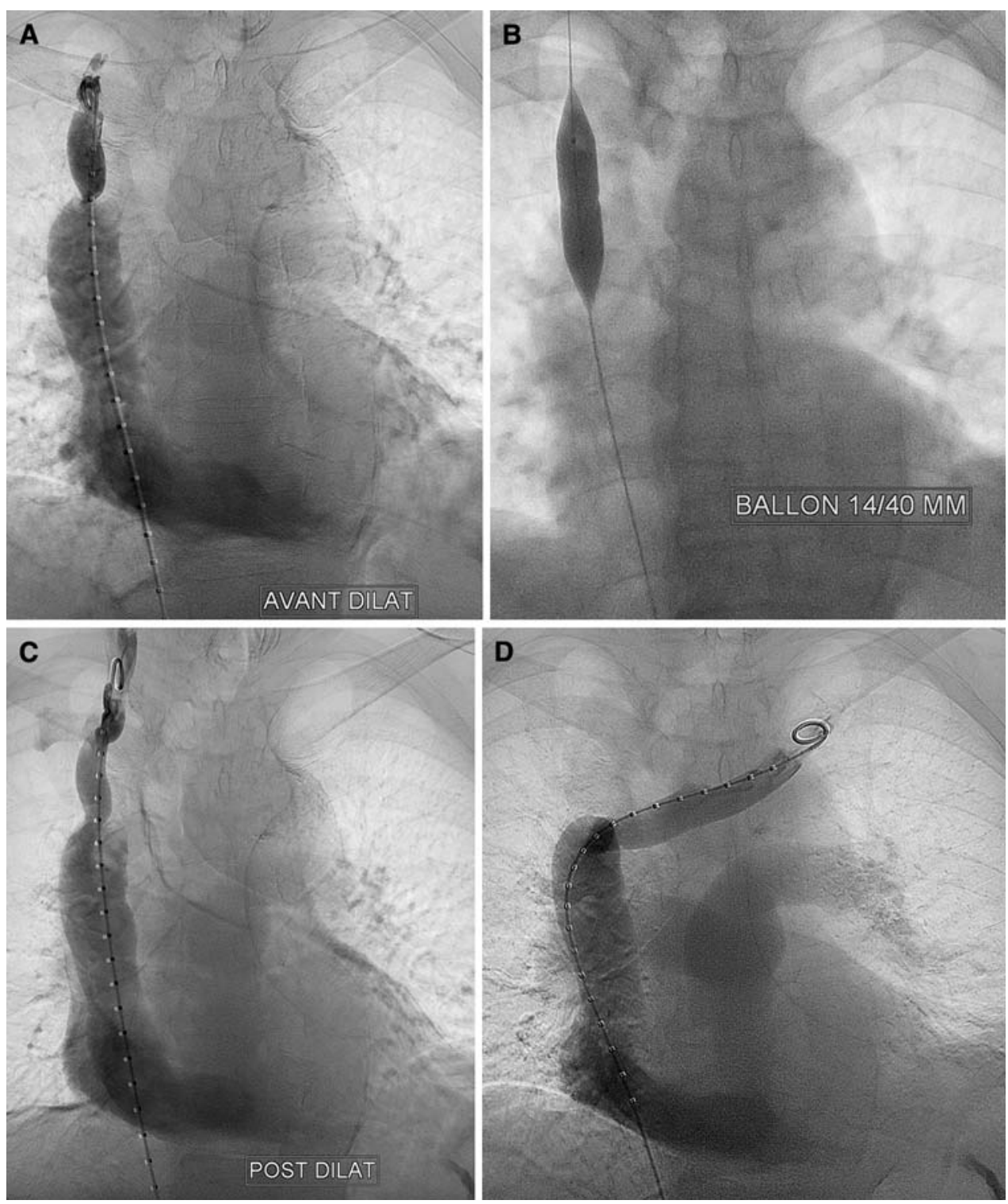

or complex stenosis in three patients $(25 \%)$, and in two patients $(17 \%)$ the procedure was done through the arteriovenous fistula. Technical success of percutaneous recannalization was $92 \%(11 / 12)$. One patient could not be recannalized. After a femoral approach the guidewire was passed through the SVC and the left brachiocephalic vein into the subclavian vein. The guidewire could not be caught either by a left jugular percutaneous approach or by a surgical subclavian approach of the occluded subclavian vein.

Three patients had only angioplasty, while six patients had angioplasty with one stent placement and three others had two stents. The stents $(n=12)$ were implanted in the brachiocephalic vein $(n=10)$ and in the SVC $(n=2)$ as listed in Table 2. HCs were successfully inserted through all recannalized accesses. Six HCs (two permanent and four temporary) were inserted by a jugular approach, which was our first choice. Five HCs (all permanent) were inserted by a subclavian approach, when the jugular access was not possible. The patient with revascularization failure of the SVC system had a femoral catheter inserted. No complication related to the procedure was observed. All patients remain asymptomatic and no patient developed SVC syndrome after the procedure and during follow-up. All HCs were functional after the procedure and we used a flow rate of $300 \mathrm{ml} / \mathrm{min}$ for hemodialysis, without any problem. The mean follow-up was 21.8 months (range, 8-48 months). At 3, 11, and 12 months, respectively, after HC placement, three patients developed HC dysfunction. In all cases, phlebography showed fibrin sheath formation, 


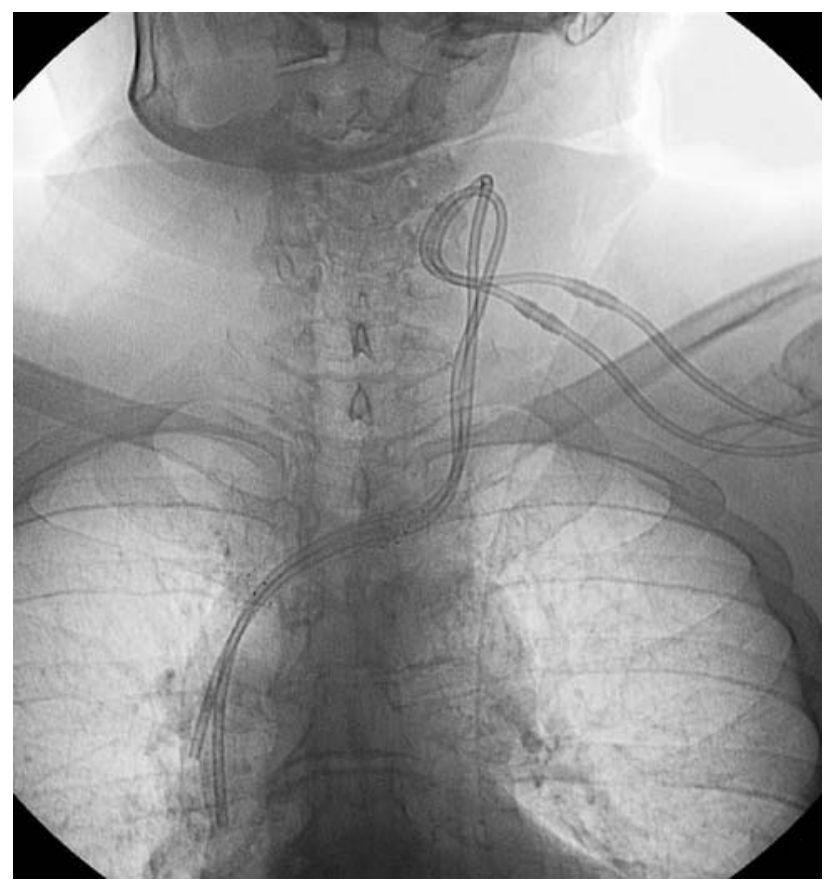

Fig. 4 Two guidewires were placed by a left jugular approach through the stent in the superior vena cava. After verification of good position of the guidewires, the catheters were placed over the wires into the peel-away sheath under fluoroscopic guidance. After the peelaway sheaths were removed and the catheter tips placed in the right position, the catheters were placed in a subcutaneous position

which was successfully managed by percutaneous endovascular stripping in two cases using a snare loop technique. In the other patients, the $\mathrm{HC}$ was removed because the arteriovenous fistula was ready for use. No bloodstream infection was noted during this follow-up and no $\mathrm{HC}$ infection was reported.

\section{Discussion}

The venous capital is of limited possibilities and we should preserve it as much as we can. This capital can be lifesaving in patients with terminal kidney disease who need dialysis. Every catheter may induce a pericatheter thrombosis, which can impair blood flow and cause vein obstruction. Considering the high incidence of catheter-related venous thrombosis, up to $60 \%$ (range, 0-60\%) [1-4], we believe that the best way to prevent venous thrombosis is to avoid catheter placement in patent veins. The organization of the thrombus may cause stenosis or chronic venous occlusion, which often remains asymptomatic [13, 14]. In the setting of chronic CTV stenosis or occlusion, venous collateral pathways may develop progressively, providing alternative routes of blood flow over time [15] and, thus, avoiding SVC syndrome. In asymptomatic patients with chronic venous obstruction, the placement of a central venous catheter may induce new venous thrombosis or impair the quality of venous collaterals, resulting in a high risk for developing SVC syndrome and catheter dysfunction.

Patients with chronic kidney disease should be advised to preserve their veins and a primary permanent arteriovenous fistula should be performed to avoid $\mathrm{HC}$ placement [16]. If no other possibility is available, the $\mathrm{HC}$ should be

Table 2 Angioplasty, stents, and catheters

\begin{tabular}{|c|c|c|c|c|c|c|c|}
\hline Patient no. & $\begin{array}{l}\text { No. of } \\
\text { stents }\end{array}$ & Type of stent ${ }^{\mathrm{a}}$ & Stent size $(\mathrm{mm})^{\mathrm{b}}$ & $\begin{array}{l}\text { Venous } \\
\text { access }\end{array}$ & Catheter $^{\mathrm{c}}$ & $\begin{array}{l}\text { Catheter } \\
\text { location }\end{array}$ & $\begin{array}{l}\text { Follow- } \\
\text { up } \\
\text { (months) }\end{array}$ \\
\hline 1 & 1 & Wallstent & $10 \times 80$ & $\mathrm{~F}$ and $\mathrm{J}$ & Bio-Flex Tesio & $\mathrm{J}$ & 48 \\
\hline 2 & 2 & Wallstent & $12 \times 60 / 12 \times 60$ & $\mathrm{~F}$ and $\mathrm{J}$ & Bio-Flex Tesio & $\mathrm{J}$ & 38 \\
\hline 3 & 1 & Philon & $12 \times 60$ & $\mathrm{~F}$ & Duo-Flex XTP & $\mathrm{J}$ & 25 \\
\hline 4 & 1 & Luminexx & $16 \times 60$ & $\mathrm{~F}$ & Bio-Flex Tesio & $\mathrm{S}$ & 24 \\
\hline 5 & 0 & & & $\mathrm{~F}$ and $\mathrm{J}$ & Duo-Flex XTP & $\mathrm{F}$ & 21 \\
\hline 6 & 2 & Luminexx & $10 \times 60 / 10 \times 40$ & $\mathrm{~F}$ & Bio-Flex Tesio & S & 21 \\
\hline 7 & 2 & Smart & $8 \times 40 / 12 \times 40$ & $\mathrm{~F}$ & Duo-Flex XTP & $\mathrm{J}$ & 19 \\
\hline 8 & 1 & Smart & $12 \times 40$ & $\mathrm{~F}$ & Bio-Flex Tesio & $\mathrm{S}$ & 18 \\
\hline 9 & 1 & Smart & $12 \times 40$ & AVF & Duo-Flex XTP & $\mathrm{J}$ & 16 \\
\hline 10 & 0 & & & $\mathrm{~F}$ & Bio-Flex Tesio & $\mathrm{S}$ & 14 \\
\hline 11 & 1 & Smart & $14 \times 60$ & AVF & Duo-Flex XTP & $\mathrm{J}$ & 10 \\
\hline 12 & 0 & & & $\mathrm{~F}$ & Bio-Flex Tesio & $\mathrm{S}$ & 8 \\
\hline
\end{tabular}

Note: $F$ femoral, $J$ jugular, $S$ subclavian, $A V F$ arteriovenous fistula

${ }^{a}$ Wallstent (Boston Scientific Corp., Natick, MA,USA); Philon (Biotronik Inc., Lake Oswego, OR, USA); Luminexx (Bard Peripheral Vascular, Inc., Tempe, AZ, USA); Smart (Cordis Corp., Miami Lakes, FL, USA)

b Diameter $\times$ length

${ }^{c}$ Bio-Flex Tesio, long-term dialysis catheter (Medcomp, Harleysville, PA, USA); Duo-Flow XTP, short-term dialysis catheter (Medcomp) 
placed in the CTV. In the case of CTV obstructions, we developed the concept of placing the $\mathrm{HC}$ on the nonfunctional venous axis to minimize the risk of developing $\mathrm{SVC}$ stenosis after HC placement. Placement of the HC in previously occluded veins (Stanford types III and IV) should preserve the venous capital and lower the risk of developing severe mechanical-related complications. The objective of the recannalization procedure is to place a functional catheter into the CTV, rather than vein patency. For this purpose, percutaneous transluminal angioplasty is sufficient to reopen the route to the CTV when there are no clots and allows HC placement. In the case of stenosis of the CTV system (Stanford types I and II), care should be taken to avoid the risk of venous obstruction and subsequent SVC syndrome after HC placement. For this reason and in the presence of blood clots, angioplasty and stent are justified [11].

Stent deployment is an established option for benign CTV stenosis [17-20]. Stents are also particularly useful in rigid, distorted, and collapsing stenoses and in treatment of vessel injuries after recannalization as well as in extrinsic fibrotic compression [21]. Placement of an undersized stent will lead to migration or thrombosis and the oversizing concept may increase pressure and stimulate intimal hyerplasia development with the occurrence of intrastent stenosis [22]. We prefer self-expanding stent oversizing, as recommended by other authors [15], with a stent diameter $15-20 \%$ greater than the vein over which it is placed. Therefore, demonstration of good blood flow through the CTV with markedly reduced collateral circulation on poststenting phlebography represents a good criterion forf immediate technical success and allows placement of the HC. Stents should always be placed in such a fashion that they do not cover the origin of other main veins or compromise future surgery. If it is not possible, no stent should be placed and angioplasty alone should be considered, especially in cases with obstruction. Long-term patency in these asymptomatic patients is not a major issue. Potential complications of stent deployment in the CTV system include venous rupture, stent misplacement, and stent migration [22, 23]. Minor venous ruptures during the percutaneous transluminal angioplasty procedure are reported to be frequent [24]. However, they usually seal spontaneously or with prolonged low-pressure inflation of the balloon. In larger venous ruptures, deployment of a stent by radial expansion can stop bleeding, while treating stenoses related to vessel injury and hematoma and avoiding the development of pseudoaneurysms [17]. In the case of venous rupture, a stent-graft is another possibility for sealing off the site of the rupture. Hemopericardium an hemothorax are rare but potential life-threatening complications. Migration of the stent is also a rare complication [25]. Late complications include recurrence of the stenosis due to intimal hyperplasia and fibrin sheath. The fibrin sheath is considered to be the first cause of catheter dysfunction [26]. During our follow-up, we observed three fibrin sheaths $(25 \%)$. Most cases of fibrin sheath can be treated by a femoral percutaneous endovascular approach and do not require removal of the HC. Placement of stents is technically and particularly delicate at the junction of the subclavian and brachiocephalic veins because of the differing luminal size compared with the CTV.

There are other alternative routes for placing a $\mathrm{HC}$ in the case of a CTV obstruction. If the stenosis is not located in the CTV, an option is another patent vein of the CTV system. But the risk of SVC syndrome is high in the case of a new pericatheter thrombosis. The femoral route, which is another alternative, should only be chosen if an access to the SVC has been excluded and is mainly reserved for temporary access [27]. The risk of infection is higher with the transfemoral approach than in the CTV system. Transrenal, translumbar, and transhepatic routes have been reported as yet other alternatives [28-31]. The translumbar access is generally preferred because of the low infection and thrombosis rates.

In conclusion, treatment of CTV stenosis or occlusion in asymptomatic patients in order to place a $\mathrm{HC}$ is a feasible and safe alternative technique for hemodialysis patients. This technique is strongly recommended for candidates who need HC placement, as it preserves the venous reserve and avoids major mechanical thrombosis after HC placement. Further evaluations are needed to define clinical indications and patient selection more clearly and to assess long-term $\mathrm{HC}$ function and the clinical impact of $\mathrm{HCs}$ placed in recannalized vein compared to HCs placed using standard routes.

\section{References}

1. Oguzkurt L, Tercan F, Torun D et al (2004) Impact of short-term hemodialysis catheters on the central veins: a catheter venographic study. EJR 52:293-299

2. Morales M, Comas V, Trujillo M et al (2000) Treatment of catheter-induced thrombotic superior vena cava syndrome: a single institution's experience. Support Care Cancer 8:334-338

3. Cassidy FP, Zajko AB, Bron KM et al (1987) Noninfectious complications of long-term central catheters. AJR 149:671-675

4. Brismar B, Hardstedt C, Jacobson S (1981) Diagnosis of thrombosis by catheter phlebography after prolonged central venous catheterization. Ann Surg 194:779-781

5. Lorente L, Henry C, Martin MM et al (2005) Central venous catheter-related infection in a prospective and observational study of 2,595 catheters. Crit Care 28:R631-R635

6. Maya ID, Allon M (2005) Outcomes of tunneled femoral hemodialysis catheters: comparison with internal jugular vein catheters. Kidney Int 68:2886-2889

7. Funaki B, Zaleski GX, Leef JA et al (1998) Radiologic placement of long-term hemodialysis catheters in occluded jugular or 
subclavian veins or through patent thyrocervical collateral veins. AJR 170:1194-1196

8. Funaki B, Zaleski GX, Leef JA et al (2001) Radiologic placement of tunneled hemodialysis catheters in occluded neck, chest, or small thyrocervical collateral veins in central venous occlusion. Radiology 218:471-476

9. Ferral H, Bjarnason H, Wholey M et al (1996) Recanalization of occluded veins to provide access for central catheter placement. J Vasc Interv Radiol 7:681-685

10. Horton MG, Mewissen MW, Rilling WS et al (1999) Hemodialysis catheter placement directly into occluded central vein segments: a technical note. J Vasc Interv Radiol 10:1059-1062

11. Qanadli SD, El Hajjam M, Bruckert F et al (1999) Helical CT phlebography of the superior vena cava: diagnosis and evaluation of venous obstruction. AJR 172:1327-1333

12. Cimochowski GE, Worley E, Rutherford WE et al (1990) Superiority of the internal jugular over the subclavian access for temporary dialysis. Nephron 54:154-161

13. Haire WD, Liegerman RP, Lund GB et al (1991) Thrombotic complications of silicone rubber catheters during autologus marrow and peripheral stem cell transplantation: prospective comparison of Hickman and Groshong catheters. Bone Marrow Transpl 7:57-59

14. DeCicco M, Matovic M, Balestreri A et al (1997) Central venous thrombosis: an early and frequent complication in cancer patients bearing long-term silastic catheter. A prospective study. Thromb Res 86:101-113

15. Evans J, Saba Z, Rosenfeld H et al (2000) Aortic laceration secondary to palmaz stent placement for treatment of superior vena cava syndrome. Catheter Cardiovasc Interv 49:160-162

16. National Kidney Foundation (2002) K/DOQI clinical practice guidelines for chronic kidney disease: evaluation, classification, and stratification. Am J Kidney Dis 39(suppl 1):S1-S266

17. Bornak A, Wicky S, Ris HB et al (2003) Endovascular treatment of stenoses in the superior vena cava syndrome caused by nontumoral lesions. Eur Radiol 13:950-956

18. De Gregorio Ariza MA, Gamboa P, Gimeno MJ et al (2003) Percutaneous treatment of superior vena cava syndrome using metallic stents. Eur Radiol 13:853-862
19. Qanadli SD, El Hajjam M, Mignon F et al (1999) Subacute and chronic benign superior vena cava obstructions: endovascular treatment with self-expanding metallic stents. AJR 173:159-164

20. Rajan DK, Saluja JS (2007) Use of nitinol stents following recanalization of the central venous oclusions in hemodialysis patients. Cardiovasc Interv Radiol 4:662-667

21. El-Sabrout RA, Duncan JM (1999) Right atrial bypass grafting for central venous obstruction associated with dialysis access: another treatment option. J Vasc Surg 29:472-478

22. Antonucc F, Salomonowitz E, Stuckmann G et al (1992) Placement of venous stents: clinical experience with self expanding prosthesis. Radiology 183:493-497

23. Gray JR, Dolmatch BL, Horton KM et al (1994) Migration of Palmaz stents following deployment for venous stenoses related hemodialysis access. J Vasc Interv Radiol 5:117-120

24. Raynaud AC, Angel CY, Sapoval MR et al (1998) Treatment of hemodialysis access rupture during PTA with Wallstent implantation. J Vasc Interv Radiol 9:437-442

25. Taylor JD, Lehmann ED, Belli AM et al (2007) Strategies for the management of SVC stent migration into the right atrium. Cardiovasc Interv Radiol 5:1003-1009

26. Duncan ND, Singh S, Cairns TD et al (2004) Tesio-Caths provide effective and safe long-term vascular access. Nephrol Dial Transpl 19:2816-2822

27. Zaleski GX, Funaki B, Lorenz JM et al (1999) Experience with tunneled femoral hemodialysis catheters. AJR 172:493-496

28. Wible BC, Hieb R, Halum R et al (2005) IVC stent deployment via translumbar approach. J Vasc Interv Radiol 16:733-736

29. Kinney TB (2003) Translumbar high inferior vena cava access placement in patients with thrombosed inferior vena cava filters. J Vasc Interv Radiol 14:1563-1568

30. Bennett JD, Papadouris D, Rankin RN et al (1997) Percutaneous inferior vena cava approach for long term central venous access. J Vasc Interv Radiol 8:851-855

31. Rajan DK, Croteau DL, Sturza SG et al (1998) Translumbar placement of inferior vena caval catheter: a solution for challenging hemodialysis access. Radiographics 18:1155-1167 